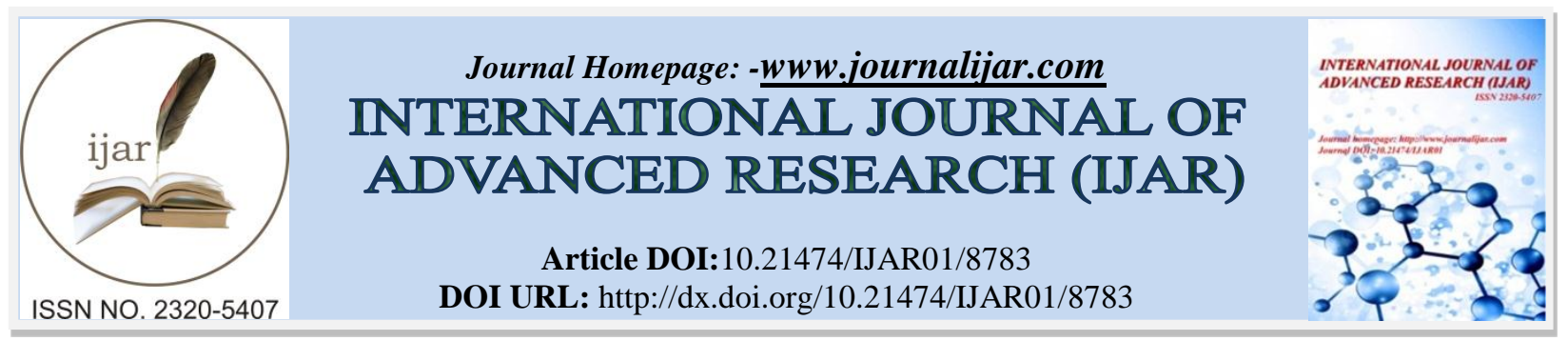

RESEARCH ARTICLE

\title{
GENDER AND TRANSFORMATIONAL LEADERSHIP IN SCIENCE, TECHNOLOGY AND MATHEMATICS EDUCATION.
}

\author{
Dr. Adesoji Olubunmi Omoniyi. \\ Department of Science Education, Adekunle Ajasin University, Akungba Akoko, Ondo State.
}

\section{Manuscript Info}

Manuscript History

Received: 02 February 2019

Final Accepted: 04 March 2019

Published: April 2019

Key words:-

gender, transformational leadership, STEM, women participation, new action plan..

\begin{abstract}
It is an undisputable fact that Science, Technology, Engineering and Mathematics (STEM) are key indices for national development. Despite considerable progress in promoting gender equality and narrowing the gender gap in Science, Technology, Engineering and Mathematics (STEM) education, women are still underrepresented, receive less recognition and disproportionately affected by economics, social, family and environmental stress, experience unequal rights, discrimination and violence in both developed and developing countries. More than half of human population is made up of women. It is on this premise that the role of women in national and international development becomes an issue when viewed from the lens of their participation in STEM disciplines. This paper therefore identified barriers to women participation in STEM education and also examined the extent of women participation in STEM. The paper proposes a new action plan for government in particular and the society in general through which women's participation in STEM education can be improved.
\end{abstract}

Copy Right, IJAR, 2019,. All rights reserved.

\section{Introduction:-}

There is a great deal of research available on the lack of gender equality in the areas of Science, Technology, Engineering and Mathematics (STEM). Similarly, there is a large body of literature on the lack of gender equality in leadership areas. Yet, there is little research into the intersection of these two area; the subject of women's leadership in STEM fields. This paper will explore the idea that the similar nature of the barriers to women's participation is STEM and in leadership, makes this an area that should be carefully studied, both in order to identify and understand the unique problems women in STEM leadership may face and to see how the two sets of barriers may interact to compound or reduce the problem of women's participation in STEM leadership.

STEM are a vast subject that deal with man's daily activity. It is however unfortunately believed that STEM is very difficult and that a person should be born extraordinarily intelligent to be able to study and understand STEM. It is also believed that male children are born scientists. The true situation is that anyone, irrespective of gender can study STEM. The above stereotyped views have created the need for up-to-date information about gender differences in the performances of female students in STEM education. The existing stereotype is enough to discourage women from entering or persisting in careers in STEM. STEMS are stereotyped as male domains. This stereotype about female inferiority in STEM is prominent among children and adolescents, parents and teachers 
where some parents believe that their sons' mathematics ability is higher than their daughters' (Stede, 2003) American Association of University Women (AAUW) in its 1999 report, stated that in mathematics and science, male students still out score female students and the gender gap increases with grade level on national and international tests such as Scholastic Assessment Test (SAT) and The International Mathematics and Science Study (TIMSS). The report further indicates that, despite the dramatic entry of the internet into our schools in the past several years, this technology is beginning to create a new gender gap.

In the same vein at local levels, many studies have shown that there is obviously very low participation of women in science related fields. Adeloye (1999); shows that there are low participation of females in mathematics, science and technology programmes in the universities in 1989 which was $21 \%$. In that same year, according to her, the ratio of men to women was 13:1. For pure science, the ratio was 3:1 in favour of males. At Adekunle Ajasin University, Akungba Akoko for example, out of the 858 students enrolled in 2015/2016 academic session in the faculty of Science, only 341 (40.21\%) are female students. Also, in the succeeding academic session 2016/2017 session, out of 1,538 students enrolled in the faculty of science, only 650 ( $42 \%$ were female students)

In Nigeria, the women on their part have set up several organizations aimed at boosting women participation in science and technology. These include Nigerian Association of Women Scientists (NAWS), Nigerian Association of Women in Science, Technology and Mathematics, Gender Studies Association of Nigeria and so on. All these steps have apparently improved women participation in the field of science and technology in various tertiary institutions across the country but not too impressive.

\section{Gender and enrolment in STEM-The Nigerian example}

1. Listed below are the enrolment figures for students in Nigerian Universities in 2014/2015 session.

2. Data in Table 1 shows females do not have up to 50\% representation in any of the STEM disciplines.

Table I:-Undergraduate students' enrollment by academic discipline and gender in federal universities in Nigeria

\begin{tabular}{|c|c|c|c|c|c|}
\hline \multirow[t]{2}{*}{$\mathbf{S} / \mathbf{N}$} & \multirow[t]{2}{*}{ Academic discipline } & \multirow[t]{2}{*}{ Total } & \multicolumn{2}{|c|}{ Gender } & \multirow[t]{3}{*}{ Remarks } \\
\hline & & & Male & Female & \\
\hline 1 & Administration & 42,509 & $25,920(61.0 \%)$ & $16,589(39.0 \%)$ & \\
\hline 2 & Agriculture & 31,577 & $19,680(62.3 \%)$ & $11,897(37.7 \%)$ & STEM \\
\hline 3 & Arts & 39,8936 & $20,106(50.5 \%)$ & $19,703(49.5 \%)$ & \\
\hline 4 & Education & 72,284 & $40,211(55.6 \%)$ & $32,073(44.4 \%)$ & \\
\hline 5 & Engineering & 52,169 & $45,706(87.6 \%)$ & $6,463(12.4 \%)$ & STEM \\
\hline 6 & Environmental sciences & 19,227 & $14,902(77.5 \%)$ & $4,325(22.5 \%)$ & \\
\hline 7 & Law & 29,852 & $19,860(67.1 \%)$ & $9,722(32.9 \%)$ & \\
\hline 8 & Medicine / dentistry & 29,791 & $187,345(58.5 \%)$ & $12,356(41.5 \%)$ & STEM \\
\hline 9 & Pharmacy & 6,128 & $3,499(57.1 \%)$ & $2,629(42.9 \%)$ & STEM \\
\hline 10 & Sciences & 129,045 & $78,342(60.7 \%)$ & $50,703(39.3 \%)$ & STEM \\
\hline 11 & Social sciences & 51,527 & $38,738(75.2 \%)$ & $12,789(24.8 \%)$ & \\
\hline \multirow[t]{2}{*}{12} & Veterinary medicine & 2,683 & $1,911(71.2 \%)$ & $772(28.8 \%)$ & STEM \\
\hline & Total & $\mathbf{5 0 6 , 3 5 8}$ & $326,310(64.4 \%)$ & $180,048(35.6 \%)$ & \\
\hline
\end{tabular}

Source: NUC Academic Standards Department

Under remarks, we have indicted the core STEM areas.

Data in Table 1 show that women have achieved more than $30 \%$ enrolment in the areas of Agriculture (37.7\%); Medicine / Dentistry (41.5\%); Pharmacy (42.9\%); and the Sciences (39.3\%). They are still behind in Engineering (12.4\%) and Veterinary Medicine (28.8\%). The apparent high enrolment recorded in Medicine and Pharmacy is because these are areas stereotyped as "soft sciences" and which are known to attract female participation.

Table 2:-Staffing in Federal Universities in Nigeria - by academic discipline and gender 2010/2011 session

\begin{tabular}{|c|c|c|c|c|c|}
\hline \multirow[t]{2}{*}{$\mathbf{S} / \mathbf{N}$} & \multirow[t]{2}{*}{ Academic discipline } & \multirow[t]{2}{*}{ Total } & \multicolumn{2}{|c|}{ Gender } & \multirow[t]{3}{*}{ Remarks } \\
\hline & & & Male & Female & \\
\hline 1 & Administration & 1,698 & $1,126(66.3 \%)$ & $572(33.7 \%)$ & \\
\hline 2 & Agriculture & 1,818 & $1,286(70.7 \%)$ & $532(29.3 \%)$ & STEM \\
\hline 3 & Arts & 1,758 & $1,052(59.8 \%)$ & $706(40.3 \%)$ & \\
\hline
\end{tabular}




\begin{tabular}{|l|l|l|l|l|l|}
\hline 4 & Education & 2,881 & $1,719(59.7 \%)$ & $1,162(40.3 \%)$ & \\
\hline 5 & Engineering & 2,731 & $2,422(88.7 \%)$ & $309(11.3 \%)$ & STEM \\
\hline 6 & Environmental sciences & 1,097 & $874(79.7 \%)$ & $223(20.3 \%)$ & \\
\hline 7 & Law & 484 & $306(62.2 \%)$ & $178(37.8 \%)$ & \\
\hline 8 & Medicine / dentistry & 2,560 & $1,583(61.8 \%)$ & $977(38.2 \%)$ & STEM \\
\hline 9 & Pharmacy & 470 & $268(57.0 \%)$ & $202(43.0 \%)$ & \\
\hline 10 & Sciences & 4,922 & $3,366(68.4 \%)$ & $1,556(31.6 \%)$ & STEM \\
\hline 11 & Social sciences & 1,496 & $1,031(68.9 \%)$ & $465(31.1 \%)$ & \\
\hline 12 & Veterinary medicine & 349 & $282(80.8 \%)$ & $67(19.2 \%)$ & STEM \\
\hline & Total & $\mathbf{2 2 , 2 6 4}$ & $\mathbf{1 5 , 3 1 5}(\mathbf{6 8 . 8 \%})$ & $\mathbf{1 8 0 , 0 4 8 ( 3 5 . 6 \% )}$ & \\
\hline
\end{tabular}

Source: NUC Academic Standards Department

In terms of Academic staff, women have reached the 30\% mark in Medicine/ Dentistry, (38.2\%); Pharmacy (43\%) and the Sciences (31.6\%). Prior to this time, female Engineers were very scarce but as at the 2014/2015 Academic year, $11.3 \%$ of lecturers in the Faculty of Engineering are females. Here again, the pattern is almost similar to that of student enrolment bringing up the issues of lack of role models as an issue in low female participation in STEM disciplines.

\section{Women in STEM discipline World Wide}

Despite efforts to give women greater access to education in science and technology in some countries, research shows that they are still significantly under-represented in many Degree Programmes, especially in engineering, physics and computer science. Even with improved physics and computer science coupled with improved access to science and technology education, women have not increased their numbers in the workforce. Infact, in some countries including the United State of America, the number of women in the science and technology workforce is declining. According to the Women in Global Science and Technology (WIGSAT, 2010), women are not having access to professional and income opportunities. Findings from a study conducted by the Organization for Women in Science for Developing World (OWSD) and the Women in Global Science and Technology (WIGSAT) with the aid of a 2010 Elsevier Foundation Grant asserted that countries are missing out on the enormous potential that women possess because they are not participating effectively in the science and technology sectors that are being designed to affect the life of a country.

\section{Barriers to Women Participation in STEM and Leadership}

Despite large gains made in several areas in science and technology, women do not still participate equally in all areas of STEM as reflected in Tables 1 and 2.

According to the National Science Foundation (2011), women are well represented in biology and the social /psychological sciences but, yet, gaps persist in physics, engineering and computer science (as reflected in table 1).

Over the years, a great deal of research has focused on the causes of this gender gap, hence, this paper shall outline some of the barriers to women participation in STEM.

\section{Discrimination and Implicit Bias}

Despite over sexism being much less common now, covert sexism and discrimination are still major factors that keep women from participating in science and technology. In a study of the factors that keep and hurt women in STEM, Settles (2006) found that discrimination and harassment were still issues. Xu (2008), noted that women were more likely to leave STEM academic environments than men because of fewer resources and lack of support.

\section{Women's participation in leadership}

This can be linked with lack of role models and mentors

Much of the literature on improving women's participation in STEM and leadership emphasizes the need for role models and mentors (Pritchard, 2006; AWIS, 1995). For women to be in leadership position, the barrier is impenetrable. There are many dead ends emanating from the socio-cultural factors in the society.

Also, in scientific and technical fields, lack of role models and mentors provides another barrier to women aspiring to leadership positions. It is hard to envision yourself as a president when you have never seen someone who looks like you in that position. Unless she has an advocate and role model, a female leader is likely to face a host of 
problems that a man would not, and she will have no one to support her and back her up. One example of the importance of advocacy in the case where a woman proposes an idea in a meeting, it is ignored, and later a man proposes the same thing and it is applauded. Also, part of the problem in encouraging women to STEM is that young girls are not presented with many examples of women in STEM areas. In a study testing how the presence or absence of female role models affect women's career preferences, Stout (2010) showed that exposure to female STEM "experts" increased positive attitudes, self-efficacy, and connection with the discipline for female college students. Much of the literature on improving women's participation in science emphasizes the need for role models and mentors (Pritchard, 2006)

\section{Discrimination, Family Obligation and Bias}

The Nigeria girl-child is discriminated against which results in less parental appreciation and care and unequal access to education according to Osakwe's (1995) report. The social and occupational stereotype indoctrination which begins from infancy and had subtly shaped the participation and attitudes of the society is another barrier militating against women's active participation in science and technology. Adeloye (1999) posited that parents always encourage their boys to go into some academically tensed courses like engineering, architecture and so on, while girls are expected to be confined to the home and family life. The culture of early marriage is a menace in some parts of Nigeria where a girl child of nine years old drop out of school for marriage (Omoniyi, A. O. 2013) even in the $21^{\text {st }}$ century, that we have gradual shift from the above perception on women education, certain courses are still regarded as being meant for a particular gender. For instance, while males dominate science courses as reflected in the case of the faculty of science, Adekunle Ajasin University, Akungba-Akoko in 2015/2016 academic session, females are encouraged to pursue such courses as Secretariat studies. Home economics and teaching.

\section{Different leadership styles and expectations of leaders}

Most commonly referenced research on leadership styles are the three proposed by James, Macgregor Burns (1978); transactional leader, transformational leaders, and laizze faire leaders. While historically male leaders have evinced transactional styles of leadership (keeping people in line, giving direction, praising and punishing), a new style of leadership has emerged that focuses on inspiring workers, promoting innovation, serving as a role model, and building community. This style, termed transformational leadership has been shown to be a more effective method of leading people (Eagly et al, 2003). This is very applicable to academic environment. Eagly et al (2003) posited that women are more likely to exhibit transformational leadership styles. In a study of female university leaders, Madson (2008) noted that these successful women often had an androgynous leadership style, with both instrumental and expressive qualities. Expectations of leadership style from someone of a particular gender can be problematic when a leader does not follow gender norms.

\section{The double bind}

Generally, women are expected to be nurturing and communal, yet leaders are supposed to be forthright and agentic. When a woman acts agentically, she is often viewed negatively or with hostility since she is acting outside her gender norms. Kathleen Hall Janieson (1995) proposed five double standards that hinder women's participation in leadership. The first is the Womb/Brain where women have to choose between being a mother or a leader. Women who choose to stay at home to raise children have little or no access to leadership opportunities. This begets a false assumption that a woman must choose between the two. The second double bind is silence/shame where women are condemned for something they are forbidden to do. Women were not allowed to speak for themselves or others, and then were derided for never standing up or speaking out. The third double blind is sameness / difference; when compared against a male norm, women losses whether they claim to be the same as men (and therefore unfeminine) or different from men (and therefore lesser). The fourth double bind is feminity/competence where a woman can be viewed as feminine or can be viewed as competent but not both. The last double bind is Aging/invisibility; as a women ages, she becomes a wrinkled croned but as man ages, he becomes wise sage. These double binds are just another example of how our society hinders women's paths to leadership.

\section{New Action plan to improve women's participation in STEM education}

1. The nature of skills required for STEM education has a peculiar nature which must be supplemented by cognitive ability with appropriate aptitude tests. The psychometricians, teachers and examination bodies can help the counsellor identify the female students that are capable of participating in STEM education right from the Junior Secondary School levels. The counselor can also make use of appropriate tests designed by test experts. Such tests will enable him to know those females who possess appropriate cognition and psychomotor 
skills to excel in STEM education instead of allowing parents to dictate to the children what they want them to become.

2. Expose girls to successful female role models in STEM. Exposing girls to successful female role models can also help counter negative stereotypes in STEM, because girls see that people like them can be successful in these fields. Role models who describe their own experiences and challenges and how they overcame them can also help students and those aspiring for leadership positions see their struggles as a normal part of the learning process rather than as a signal of low ability.

3. Teach students about stereotype threat. Researches have shown that the existence of a negative stereotype (for example, "boys are better than girls in mathematics") and adversely affects the test performance of members of the negatively stereotyped group. This phenomenon is known as stereotype threat. Teaching students explicitly about stereotype threat can minimize effect.

4. Encourage and help girls to develop their spatial skill (Mathematics Skills). One of the largest and most persistent gender differences in cognitive skills is in the area of spatial skills, where boys consistently outperform girls. Spatial skills are important for success in engineering, chemistry and other STEM fields. Girls with well-developed spatial skills may be more confident about their abilities and express greater interest in pursuing STEM subjects in elementary school. A well-developed spatial skill also promotes persistence in engineering in the university. Girls should be provided with opportunities to develop their spatial skills by encouraging them with constitution of toys, 3-d computer games, sketch drafting and mechanics.

5. Emphasis should be placed on the relevance of STEM education to learners. This can be done by the STEM teachers during lessons by pointing out the areas of application of the STEM concepts they are teaching to life outside the schools. STEM should be taught to students in a way that they will see the relevance of STEM in their day-to-day activities and in solving some of their problems. Making science relevant to everyday life of the learners will increase their motivation, interest, and participation in the subjects irrespective of gender.

6. There should be enlightenment campaign where parents should be sensitized on the need to keep their female children in school instead of giving them out in marriage at an unripe age.

\section{Conclusion:-}

The issues that hinder women's participation in STEM education have a large overlap with the issues hindering women's participation in leadership. Implicit biases and discrimination, family obligations, and lack of role models and mentors are just a few on the problems facing society and the women trying to succeed in their chosen careers. Government needs to be promoting STEM education to everyone. Talented female individuals in our society should not be turned away. They should be allowed to exhibit the naturally endowed potentials in them. Not only are women needed in the field of STEM education, women are needed to be leaders both for their own sake and to serve as role models for the next generation of women in STEM. The lack of research on women leadership in STEM is itself another barrier to overcome in pursuit of the critically important goal of truly equitable participation in science, technology, engineering and mathematics. 


\section{References:-}

1. Adeloye, J. A. (1999). Towards a Realistic Participation of Women in Technological Education in the 21st century and beyond. The Guidance factors. JOWICE 3:109-113.

2. Akande, F.F.(2001). Promoting Women's Active Participation in Science, Technology and Mathematics Education: A Guidance Counsellor's perspective. The Nigerian Academic Forum. Vol. 1 No. 5.

3. American Association of University Women (AAUN) 1999 report

4. Awis (1995). A Hand Up: Women Mentoring Women in Science, Washington, DC: Association for Women in Science.

5. Burns, J.M.1978. Leadership. New York: Harper and Row

6. Eagly, A. H; M.C. Jahannesen -Schmidt, and M.L. VanEengen (2003). Transformational, transactional and laisseafaire leadership styles: A meta-analysis comparing women and men psychological Bulletin 129:569591.

7. J. Steele (2003). Children's Gender Stereotypes About Math: The Role of Stereotype Stratification. Journal of applied social psychology. Wiley online library

8. Keller, E. F. (1985). Reflections on gender and science, New Haven, Co: Yale University Press.

9. National Science Foundation (US)., (2011). Women, Minorities and persons with Disabilities in Science and Engineering:2011. http://www.nsf.gov/statistics/unmpd

10. Omoniyi A.O and K.O Oloruntegbe (2013). Access and attrition of female students in secondary school in the Federal Capital Territory. Journal of African Studies and Development 5(2),717-814.

11. Organization for Women in Science for Developing World (OWSD) \& Women in Global Science and Technology (WIGSAT) 2010.

12. Pritchard, P.A(ed) (2006). Success strategies for women in science: A portable mentor. Burlington, MA: Elsevier Academic Press.

13. Settles, I. H; L.M. Cortina; J. Malley, and A.J Steward. The climate for women in academic science: The good, the bad, and the changed. Psychology of women Quarterly 30:47-58.

14. Stout, J.G., N. Dasgupta, M. Hunsinger. (2010). STEMing the tide: using in group experts to inoculate women's self-concept in Science, Technology, Engineering and Mathematics (STEM). Journal of personality and social psychology 100:255-270.

15. U.S Department of commerce economic and statistics administration. (2011). Women in America. Indicators of Social and Economic Well-Being. http//www.whitehouse.gov/sites/default/files/rssviewer/women in America.pdf.

16. Uchenna M. N; Queendaline O.I. (2017). Building a science, technology, engineering and mathematics (STEM) pipeline for girls and women. New perspectives in gender studies in Nigeria. 153-163.

17. Xu, Y. J. (2008). Gender disparity in STEM disciplines: A study of Faculty attrition and turnover intentions. Research in Higher Education 49:607-624. 